\section{Compliance, deterrent threats, and the need to save face*}

\author{
DOUGLAS F. JOHNSON \\ The University of Rochester, Rochester, N.Y. 14627
}

Deterrent threats have been shown to lead to a high level of compliance in certain situations. But when a person feels strong need to save face, deterrent threats become dramatically less successful in eliciting compliance in these same situations. The data indicate that the S's perceptions of the situation change when there is a high need to save face and that a threat made by an opponent may be viewed as an assault on the person himself and his self-perceptions.

Preliminary unpublished research suggests that the type of threat affects the level of compliance in a competitive situation. Specifically, a deterring threat ("don't do it") that closes off just a few of the opponent's behavioral options leads to the most compliance. A compelling threat ("you must do that") leads to the least compliance. In that study, a deterrent threat given relatively early in the behavioral sequence was found to result in virtually $100 \%$ compliance.

Several investigators have shown that the need to maintain face increases conflict in interpersonal bargaining. Brown (1968) used a programmed stooge to exploit Ss systematically. Some of the Ss received feedback from an audience telling them they looked foolish and weak. Others, although similarly exploited, were told they looked good. He found that humiliated Ss were more likely to retaliate, and with greater severity, than those who received favorable feedback. Most importantly, retaliation occurred even though it required sacrificing available outcomes. Deutsch (1969) reports that in a bargaining situation, male Ss run by a female $\mathrm{E}$ experienced greater difficulty in reaching a cooperative settlement than did those run by a male. It was felt that in the former condition, the need to save face was greater, so that the Ss experienced the situation as a more competitive one. Pruitt \& Johnson (1970) have obtained similar results; the need to save face decreases the likelihood that an acceptable agreement will be reached between two bargainers unless there is intervention from an outside source.

The purpose of the present study was to determine the effect of need to save face on compliance to a deterrent threat. it was hypothesized that a high need to save face would dramatically

\footnotetext{
* Paper presented at the Eastern Psychological Association Annual Convention, April 1971.
}

reduce the level of compliance to the threat.

\section{SUBJECTS}

The Ss were 20 male undergraduate students from an introductory psychology course at the State University of New York at Buffalo. They were fulfilling a class requirement for experimental participation and were, in addition, promised remuneration based on their performance in the task.

\section{PROCEDURE}

Each experimental session involved two Ss who were seated at opposite 30 -in. barrier. It was explained that the Ss were not to communicate with each other except in a manner to be described later. experiment was concerned with competition between large groups such as corporations or nations and that they should consider themselves the sides of a table but separated by a

The Ss were told that the Nation B. decision maker for a large group. Further, the situation was such that there was a limited set of goals that might be pursued, with each goal representing a different magnitude of value. Two restrictions were added: only one $\mathrm{S}$ could attain a given goal, and one of the Ss would be given a power that the other didn't have. The Ss were then purportedly randomly assigned to the nation that they would represent.

The task used can be seen in Fig. 1 . The Ss were given what was to be considered a map. This map showed both Nations $A$ and B. Each nation had a choice of three possible goals. Two of the goals were in common, meaning that both nations might try for them. If they attained Goal Z, they would be awarded 3,000 points, Goal $Y, 1,000$ points, and for their noncommon goal, 300 points. The money that they would be paid was dependent on the number of points they earned in the task. It was explained that if both nations tried for the same goal, the one who reached it first got the prize, the other got nothing. Each $\mathrm{S}$ was given 21 chips. Each chip represented permission to occupy one of the spaces on the way to a goal. Moves had to be made in consecutive spaces. A chip could be used to move one space towards a goal, one move away from a goal, or to continue to occupy a space that had previously been occupied. The Ss alternated making moves toward the goal of their choice, with the $S$ having less power getting the first move on each trial. It was explained that as

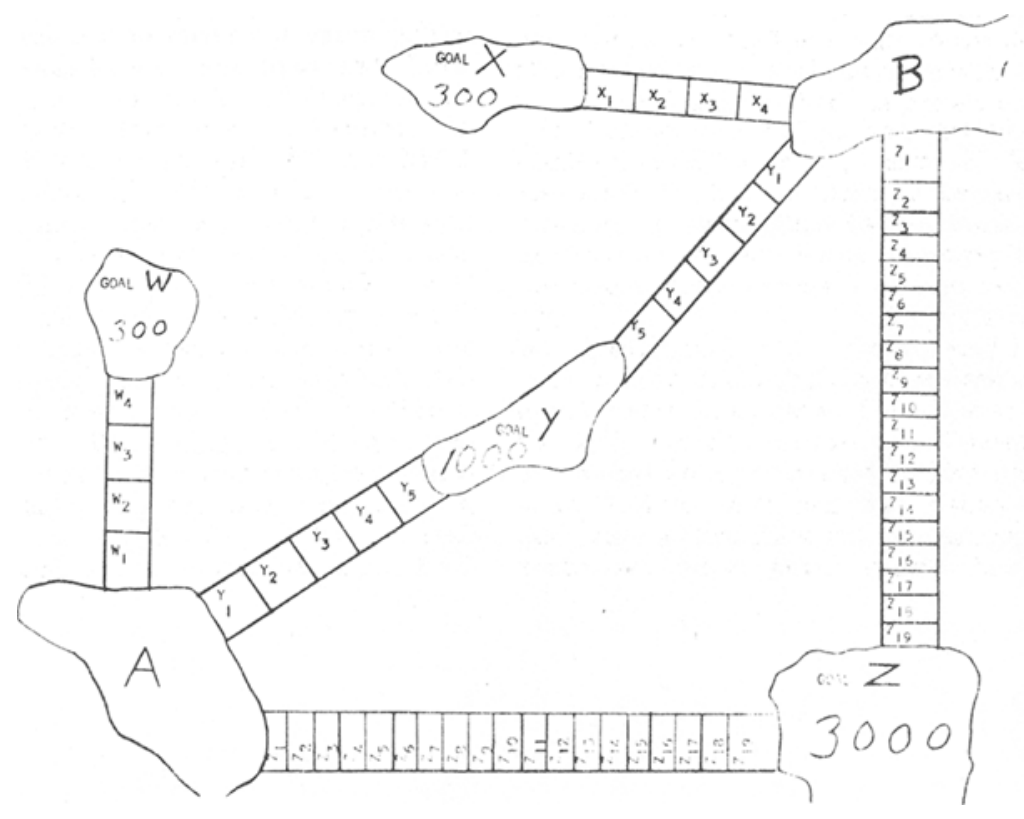

Fig. 1. The experimental task. The $S$ was Nation $A$ and the confederate 
Table 1

Means and Variance for Behavioral and Questionnaire Data

\begin{tabular}{|c|c|c|c|c|}
\hline \multirow[b]{2}{*}{ Item } & \multicolumn{2}{|c|}{ Means } & \multicolumn{2}{|c|}{ Variance } \\
\hline & HFS & LFS & MS Bet. & MS Wit. \\
\hline (1) Behavior & 1.2 & 0.1 & 6.1 . & 4 \\
\hline (2) Self: friendly-unfriendly & 3.8 & 2.3 & 11.3 & 2.1 \\
\hline (3) Self: competitive-cooperative & 2.7 & 3.9 & 7.2 & 2.2 \\
\hline (4) Other: foolish-clever & 3.6 & 5.7 & 22.1 & 3.0 \\
\hline (5) Other motivated by selfishness (yes-no) & 4.1 & 2.8 & 8.5 & 3.1 \\
\hline (6) Other motivated by greed (yes-no) & 4.2 & 2.1 & 22.1 & 2.4 \\
\hline (7) Importance of avoiding fine (high-low) & 5.6 & 4.9 & 20.0 & 2.8 \\
\hline
\end{tabular}

Vote-All questionnaire items are 7 -point scales: HFS = high face saling. $L F S=$ lou face sauing.

soon as a nation reached one of the goals, the experiment was over for him, and that he would be awarded as many points as the goal was worth.

It was further explained that Nation B had a power Nation A did not have. That power consisted of the ability to cause Nation $A$ to lose points from his overall total. Nation B would not get any points Nation A lost-in essence, they would go back to the $E$. This could be considered similar to a fine. It was explained that B could use this power or not, as he wished.

In actuality, one of the Ss was an experimental accomplice. The confederate was always assigned to the role of the more powerful nation. His behavior was restricted so that he always attempted to gain the most valuable goal. After the $S$ made his first move, the confederate sent a note to $S$ attempting to dissuade him from attaining the most valuable goal. ${ }^{1}$ The confederate sent only this one communication to $S$ during the course of the experiment. The $S$ was not allowed to communicate with the confederate. After the threat was delivered, the confederate continued to move towards the most valuable goal regardless of the behavior of $S$.

At the end of the experiment, the real $S$ was given a questionnaire designed to measure the effectiveness of the independent variables, measure self-perceptions and perceptions of the other, and to measure reactions to the threat.

There were two conditions of interest in this study: high vs low need to save face. In both conditions, the $S$ received a deterrent threat. The Ss were told that all of their moves would be called out and then plotted on a large map on the wall; in this way, one would always know what the other was doing. In the high face-saving condition, the person who observed their behavior and plotted the moves was an attractive female. In the low face-saving condition, this role was performed by a male. It has been found that in a competitive situation, male Ss would be more concerned with their self-presentations in front of a female audience than in front of a male audience.

The threat given to the $S$ was worded as follows: "I do not want you to go to Goal Z. If you go to Goal Z I will fine you 3,000 points."

The 20 Ss were assigned randomly, 10 per cell, to the two conditions.

\section{RESULTS}

The S's behavior was coded into one of three categories: $0=$ immediate and total compliance, $1=$ immediate noncompliance but an eventual turn around to compliance, and $2=$ immediate and total noncompliance. In the high face-saving condition, the frequencies of these behaviors were 2,4 , and 4 , while in the low face-saving condition, it was 9 , 1 , and 0 . An $F$ test and an exact multinomial were carried out on these data. The multinomial indicated that the probability of getting this pattern of results or one more deviate is $1.256 \times 10^{-5}$. Reference to Table 1 will show that in the high face-saving condition, there was significantly less compliance to the threat than in the low face-saving condition, $F(1,18)=16.75, p<.01$. Each $S$ had also filled out a questionnaire. These data indicate that the high face-saving condition people saw themselves as less friendly, $F(1,18)=5.37, p<.05$, less cooperative, $F(1,18)=3.24$, $\mathrm{p}<.10$, and saw the other as more foolish, $F(1,18)=7.28, p<.01$. They further saw the other as less motivated by selfishness, $F(1,18)=2.72, p<.10$, and greed, $F(1,18)=9.34, \quad p<.01$. Finally, the high face-saving people found it less important to avoid the fine, $F(1,18)=7.03, p<.01$. DISCUSSION

The data show that when there is a strong need to save face, threats that are usually quite successful in eliciting compliance suddenly are no longer effective. The questionnaire data give some insights into the possible reasons for this. This game is usually seen as one of economic competition. When a threat is used, it is because the other is trying to win the most money. When there is a strong need to save face, this perception of the other no longer holds. In this case, the other is no longer motivated by selfishness or greed. Similarly, the $S$ himself becomes less friendly and more competitive. The need to save face has caused a drastic change in the definition of the situation. It might be asserted that in a high need to save face condition, the other is not seen as primarily trying to gain the economic rewards, but is instead viewed as launching an attack on one's self-conception. The other has turned competition into a personal assault.

If this line of reasoning is valid, then one can see implications in all areas of interpersonal relations. As one example, one can see the wisdom of delivering threats in private or in a secret meeting. The credibility of a threat may be increased by announcing it to the world, but publicly putting a person on the spot can only defeat one's purpose if that purpose is influence.

\section{REFERENCES}

BROWN, B. $R$. The effects of need to maintain face on interpersonal bargaining. Journal of Experimental Social Psychology, 1968, 4, 107-122.

DEUTSCH, M. Socially relevant science: Reflections on some studies of interpersonal conflict. Presidential address before the Eastern Psychological Association on April 11, 1969.

PRUITT, D. G., \& JOHNSON, D. F Mediation as an aid to face saving in negotiation. Journal of Personality \& Social Psychology, 1970, 3, 239-246. NOTE

1. Only Ss who attempted to attain Goal $Z$ were of interest. Two Ss were dropped from the analyses because they did not move towards Goal $Z$ on their first move. 